\title{
LETTERS TO EDITOR
}

\section{SUCCESSFUL MATERNAL AND FETAL OUTCOME OF GUILLAIN-BARRÉ SYNDROME COMPLICATING PREGNANCY}

Sir,

Guillain-Barré syndrome (GBS) affects 6-24/100,000 of population during pregnancy. ${ }^{[1]}$ It is an uncommon neurological disorder associated with demyelinization of the peripheral nerves, more often seen in the first 2 weeks of puerperium ${ }^{[2]}$ than in pregnancy. Neuropathic symptoms are usually preceded either by Epstein-Barr virus, cytomegalovirus or campylobacter infection by 1 to 3 weeks. Herein, we report a patient of GBS who presented in the second trimester of pregnancy.

A 25-year-old gravida 3 para 2 woman reported to us at 21 weeks of pregnancy, with calf pain of 3 days' duration. This was followed by weakness in both the lower limbs, preceding flu-like infection. Neurological evaluation revealed bilateral facial and limb weakness, areflexia and generalized paresthesia. She had progressive ascending paralysis with involvement of the upper limbs on day 2 of illness, followed by trunkal weakness without bladder, bowel and sensory involvement in the next 3 days. Maximal deficit seen at the peak of illness on day 4 was acute flaccid motor paralysis. The cranial, autonomic and respiratory systems were not involved. She did not require mechanical ventilation. Nerve conduction tests and cerebrospinal fluid (CSF) analysis findings suggested diagnosis of GBS. Cytomegalovirus (CMV) serology was negative. Her treatment was immediately started with intravenous immunoglobulin (IVIG) $2 \mathrm{mg} / \mathrm{kg}$, which was continued for 5 days. Her recovery was fast with improvement in muscle weakness. On day 21 of illness, she was discharged; she could move her limbs and paresthesia had also improved. She had an outlet forceps-assisted delivery (to reduce second stage of delivery) at 37 weeks; a healthy female baby weighing $2.8 \mathrm{~kg}$ with an Apgar score of 9/9/10 was born. There was no sign of birth asphyxia in the newborn. Her puerperium was uncomplicated; power in the limbs gradually improved, and she was discharged in a stable condition after 5 days of delivery with no disability. She has no residual sequelae at 3 months' follow-up postpartum.

GBS is a rare acquired neurological disorder and is usually preceded by a bacterial or viral infection. GBS has also been linked to underlying systemic diseases, certain malignancies, surgery, pregnancy, trauma, severe infection and tissue transplantation; acute CMV infection complicating twin pregnancy has been reported by Magon et al. ${ }^{[3]}$ There have been reports of GBS in pregnancy in all the 3 trimesters and postpartum as well. Postpartum flares are common due to delayed hypersensitivity as reported by da Silva et al., when GBS was diagnosed at 15 weeks of pregnancy and aggravated postpartum; she was managed by mechanical ventilation, IVIG, corticosteroids and tracheostomy. ${ }^{[4]}$ Vijayaraghavan et al. have also described its management at 16 weeks of pregnancy. [5] Pathophysiology of GBS is still unclear, 
but an immune-mediated process may be a consequence. Although its pathogenesis is unclear, it is likely to be a consequence of an immune-mediated process. Risk of prematurity is low, and occasionally fetal death may occur. Poor prognostic factors are serious deficits in muscular balance, the need for assisted ventilation and reduced amplitude of evoked motor potential. Immunomodulation with plasmapheresis and IVIG have been found to improve treatment outcome; $70 \%$ to $80 \%$ of patients recover fully. The efficacy of IVIG has been proven. IVIG is recommended for the treatment of Guillain-Barré syndrome (level A) and can be combined with prednisone in relapses during pregnancy or postpartum period. ${ }^{[6]}$ Mehndiratta et al. described the efficacy and cost-effectiveness of current therapies in GBS. ${ }^{[7]}$ Goyal et al., from our institute, have described the management of a primigravida presenting at 26 weeks' gestation with plasmapheresis. ${ }^{[8]}$ Hence an obstetrician must be vigilant if a pregnant woman complains of generalized muscle weakness and respiratory discomfort.

To conclude, early diagnosis and prompt intensive multidisciplinary supportive care followed by IVIG therapy is advantageous in a GBS-complicated pregnancy and improves the prognosis for both mother and fetus.

ANUPAMA BAHADUR, NUPUR GUPTA, DEEPIKA DEKA, SUNEETA MITTAL

Department of Obstetrics and Gynecology, All India Institute of Medical Sciences, New Delhi, India

Correspondence: Dr. Nupur Gupta, D-34, First Floor, Pamposh Enclave, Greater Kailash-1, New Delhi - 110 048, India E-mail: nupurkothari2000@yahoo.com

\section{REFERENCES}

1. Batashki I, Markova D, Milchev N, Uchikova E, Dimitrova E. A case of Guillain-Barre syndrome in puerperium. Akush Ginekol (Sofiia) 2007;46: 48-50.

2. Cheng $Q$, Jiang $G X$, Fredrikson $S$, Link $H$, de Pedro-Cuesta J. Increased incidence of GuillainBarré syndrome postpartum. Epidemiology 1998;9:601-4.

3. Magoń T, Obrzut B, Kluz S, Chruściel A, Skret A. Guillain-Barre syndrome during CMV infection complicating twin pregnancy: A case report. Ginekol Pol 2004;75:638-41.

4. Campos da Silva F, de Moraes Paula G, Dos Santos Esteves Automari CV, Mendes de Almeida DS, Ubirajara Cavalcanti Guimarães R. GuillainBarre syndrome in Pregnancy: Early diagnosis and treatment is essential for a favourable outcome. Gynecol Obstet Invest 2009;67:236-7.

5. Vijayaraghavan J, Vasudevan D, Sadique N, Rajeswari KS, Pondurangi M, Jayshree. A rare case of Guillain-Barre syndrome with pregnancy. J Indian Med Assoc 2006;104:269-70.

6. Elovaara I, Apostolski S, van Doorn P, Gilhus NE, Hietaharju A, Honkaniemi J, et al. EFNS guidelines for the use of intravenous immunoglobulin in treatment of neurological diseases: EFNS task force on the use of intravenous immunoglobulin in treatment of neurological diseases. Eur J Neurol 2008;15:893-908.

7. Mehndiratta MM, Chowdhury D, Goel V. Efficacy and cost effectiveness of current therapies in Guillain Barre syndrome. J Assoc Physicians India 2001;49:459-69.

8. Goyal V, Misra BK, Singh S, Prasad K, Behari M. Acute inflammatory demyelinating polyneuropathy in patients with pregnancy. Neurol India 2004;52: 283-4.

DOI: 10.4103/0019-5359.58882 